\title{
Avaliação rápida de impactos em cavernas turísticas do Parque Estadual de Terra Ronca, Goiás, Brasil
}

\author{
Rapid impact assessment on touristic caves of Terra Ronca \\ State Park, Goiás, Brazil
}

Vinícius Galvão Zanatto, Programa de Pós-graduação em Geografia, Universidade de Brasília, Instituto de Desenvolvimento Sustentável Mamirauá, Brasil, vini.galvaozanatto@gmail.com

(1) https://orcid.org/0000-0002-9509-5094

Bárbara Costa Silva, Departamento de Geografia, Universidade de Brasília, Brasil, barbaracosta2@yahoo.com.br

(1) https://orcid.org/0000-0002-5348-8340

Wallace Vieira da Silva, Departamento de Geografia, Universidade de Brasília, Brasil, wallacevds22@gmail.com

(1) https://orcid.org/0000-0001-5001-3238

Venícius Juvêncio de Miranda Mendes, Centro Universitário Projeção, Brasil, venicius.unb@gmail.com

(1) https://orcid.org/0000-0002-7774-0694

Valdir Steinke, Programa de Pós-Graduação em Geografia, Universidade de Brasília, Brasil, valdirsteinke@gmail.com

(1) https://orcid.org/0000-0002-8738-6975

Resumo: O Parque Estadual de Terra Ronca se localiza nos municípios de São Domingos e Guarani de Goiás. A motivação turística na região é relacionada ao geoturismo, em especial com a visita às cavernas. Os ambientes cársticos possuem dinâmica própria o que cria ambientes singulares. Visando a conservação desses ambientes empregam-se ferramentas de diagnóstico ambiental focando nos impactos existentes na área. A pesquisa ocorreu em 4 cavernas do Parque Estadual de Terra Ronca e foi aplicado um protocolo de avaliação de impactos, elaborado por Donato et al (2014), para diagnosticar a situação das cavernas abertas ao turismo no parque, chegando aos seguintes valores de impactos: São Mateus - 21, São Bernardo - 29, Terra Ronca II - 34 e Terra Ronca - 40. Os resultados demonstraram que as cavernas estão em risco e suscetíveis a diversos impactos, sendo necessárias medidas urgentes para a conservação dos ambientes associados a elas. A implementação do plano de manejo, específico para cada caverna, é urgente, visto que esse documento é fundamental para guiar as ações de manejo e monitoramento das cavernas em questão. É importante destacar que além de tais iniciativas é preciso estabelecer programas paralelos de educação e difusão da importância destes geossistemas, propiciando conhecimento da sociedade em geral sobre cavernas e sua conservação.

Palavras-chave: Geoconservação; Áreas protegidas; Impactos do turismo; Carste.

Abstract: Terra Ronca State Park is located in the municipalities of São Domingos and Guarani de Goiás. The tourist motivation in the region is related to geotourism, especially with the visit to the caves. Karst environments have their own dynamics, which create unique environments. Aiming at the conservation of these environments, environmental diagnostic tools are employed focusing on the existing impacts in the area. The research occurred in 4 caves of Terra Ronca State Park, and an impact assessment protocol was applied, developed by Donato et al. (2014), to diagnose the situation of caves open to tourism in the park, reaching the following impact values: São Mateus - 21, São Bernardo - 29, Terra Ronca II - 34 and Terra Ronca - 40. The results showed that the caves are at risk and susceptible to several impacts, requiring urgent measures for the conservation of the environments associated with them. Implementation of the specific management plan for each cave is urgent, as this document is fundamental to guide the management and monitoring actions of the caves in question. It is important to highlight that in addition to such initiatives it is necessary to establish parallel programs of education 
and diffusion of the importance of these geosystems, providing knowledge of the general society about caves and their conservation.

Keywords: Geoconservation; Protected areas; Tourism impacts; Karst.

\section{Introdução}

O gerenciamento das atividades turísticas em unidades de conservação demanda um conhecimento científico consistente sobre os ambientes afetados pelas atividades (Lobo et al., 2015). O Parque Estadual de Terra Ronca (PETER) está localizado nos municípios de São Domingos e Guarani de Goiás e é uma das maiores regiões cavernícolas do país. A motivação turística na região está relacionada ao geoturismo, em especial com a visita às cavernas. As cavernas são espaços extremamente frágeis, com ambientes suscetíveis a mudanças e atividades em seu interior e nas proximidades (Hobo, 2011).

Para que o monitoramento e as ações de mitigação dos impactos possam ser praticados, é necessária a implementação de avaliações baseadas em critérios quantitativos e qualitativos rigorosos e passíveis de adaptação às singularidades de cada área. Assim, sugere-se a adoção de estratégias que visem a identificação das áreas mais comprometidas, por meio de indicadores, paralelas ao processo de conscientização dos visitantes.

As cavernas consistem em formações subterrâneas profundas ocorrentes em terrenos calcários (Guerra, Guerra, 2015). Esses terrenos são chamados na geomorfologia de "Relevos Cársticos". Para Hardt (2008, p. 1297) "O carste é um tipo de paisagem, onde o intemperismo químico, através da dissolução, determina as formas de relevo", isto é, são formações em rochas essencialmente calcárias onde os processos de dissolução são intensos e rápidos, permitindo a formação de dinâmicas hídricas subterrânea e ocorrência de cavernas, dolinas, grutas, sumidouros, estalactites e estalagmites (Guerra, Guerra, 2015).

Por conta dessas peculiaridades, estes ambientes cársticos são extremamente sensíveis e devem ser preservados. São constituintes do patrimônio natural e por isto protegidos por leis, como o inciso X do Art. 20 da Constituição Federal de 1988 e a Resolução CONAMA ( $\left.n^{\circ} 347 / 2004\right)$. Todavia a maioria das cavernas encontram-se de alguma forma degradadas sendo necessário realizar estudos que promovam a integração das leis com o uso e preservação dos recursos.

Sabe-se que as cavernas possuem geossistemas diferentes e complexos entre si e isto deve ser levado em consideração quando se trata de trabalhos que visam a conservação e preservação, principalmente sob perspectivas das modificações causadas neste ambiente pela presença de atividades que o ser humano exerce e também pela própria dinâmica hídrica do relevo, já que a manutenção do fluxo de drenagem é essencial para que a caverna preserve sua dinâmica hídrica.

Desta forma, segundo Hardt (2008, p. 1302) "solo, cobertura vegetal, aquífero, também são suscetíveis de sofrerem impacto em atividades turísticas e recreacionais, 
tornando a atividade turística uma contraposição à conservação ambiental. Possibilitar o turismo evitando ao máximo os danos provocados por este, é o desafio a ser vencido". Assim o plano de manejo é um dos instrumentos para tal, onde se deve pensar quais são os tipos de impactos, a capacidade de suporte destes ambientes levando em consideração a fauna, flora e a formação rochosa em si, o controle de visitantes e zonas propícias ao uso (Marra, 2001).

Estes planos de manejos devem ser integrados às metodologias apropriadas e que indiquem a vulnerabilidade, risco de extinção ou grau de estabilidade, relacionando a caverna estudada com o seu ambiente, conforme refere Donato et al. (2014), já que o ambiente interno destas feições está sob efeito dos impactos externos como o uso dos solos e atividades agropastoris.

Para o correto diagnóstico Donato et al. (2014) apontam que as cavernas devem ser caracterizadas de acordo com categorias que permitem o entendimento acerca de sua situação e indicando áreas afetadas que necessitam de recuperação. Este modelo é mais adequado à realidade brasileira já que leva em conta os aspectos geológicos, geomorfológicos, bióticos, hidrológicos e os impactos ambientais em escala regional.

A área delimitada para a pesquisa corresponde a quatro cavernas inseridas no Parque Estadual de Terra Ronca (Figura 1). O Parque Estadual de Terra Ronca foi criado no ano de 1989 , sendo a primeira unidade de conservação estabelecida nesta área. O parque foi instituído mediante a promulgação da Lei n ${ }^{\circ}$ 10.879, de 7 de Julho de 1989. Entretanto os limites da unidade só foram estabelecidos sete anos depois, a partir do Decreto 4.700, de 21 de Agosto de 1996.

Foram estabelecidos como objetivos da área a preservação da flora, fauna, mananciais, e em especial, as áreas de ocorrência de cavernas e seu entorno, protegendo sítios naturais de relevância ecológica e de importância turística reconhecida (Lei $n^{\circ} 10.879,1989$ ). No interior do parque existem cerca de 50 cavernas. Destas, cinco se destacam no turismo, sendo elas: Terra Ronca, Terra Ronca II, São Mateus, São Bernardo e Angélica.

As cavernas selecionadas para avaliação foram as principais cavidades utilizadas para a prática geoturística (Terra Ronca, Terra Ronca II, São Bernardo e São Mateus). Nesse sentido, a avaliação se deu pensando principalmente no impacto causado pela visitação desordenada. Entretanto, estes não foram os únicos impactos encontrados, portanto outros impactos e características foram avaliadas em conjunto. 


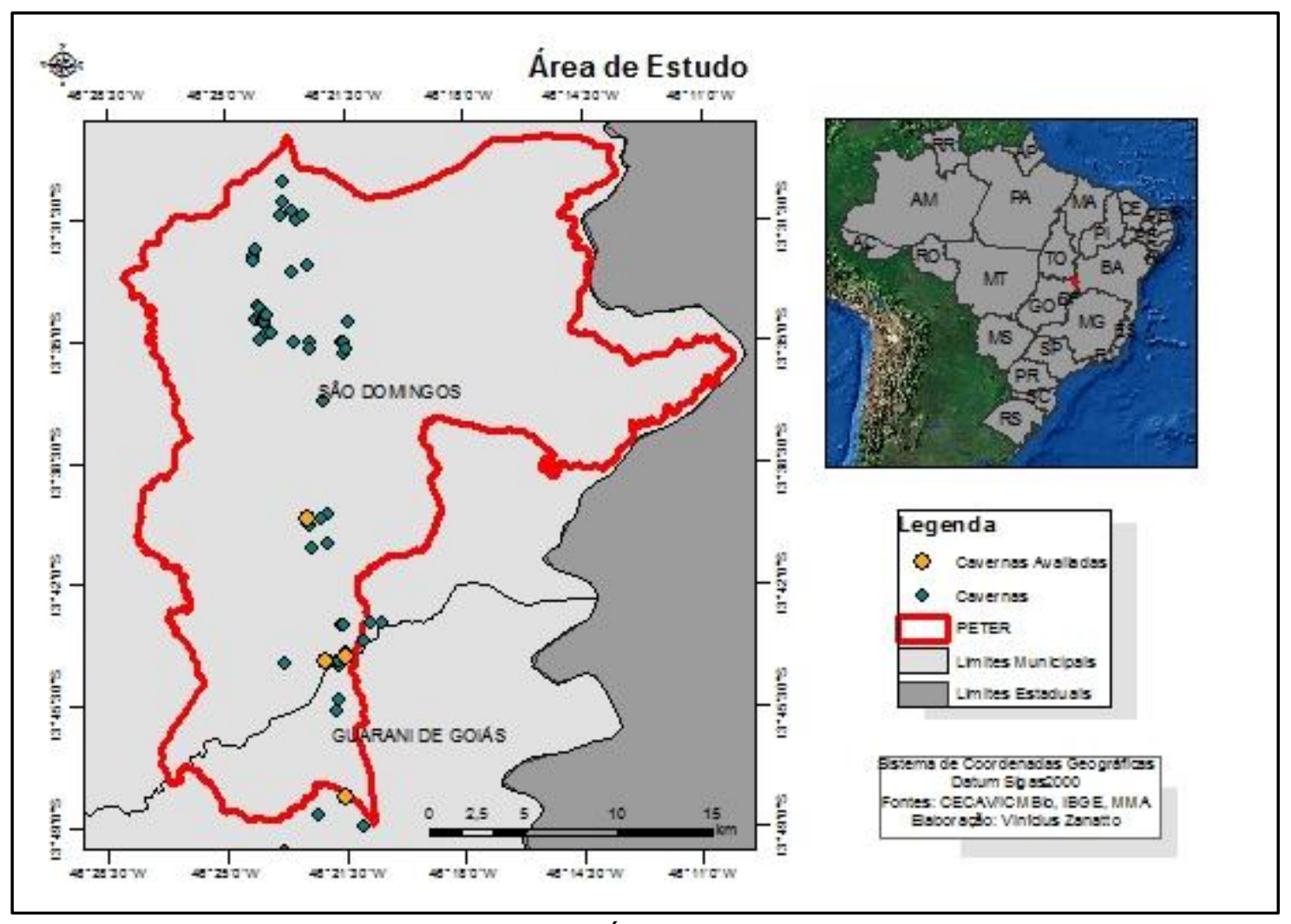

Figura 1: Área de Estudo.

Como a pesquisa é voltada para a avaliação da prática do geoturismo em cavernas, se faz necessário conceituar o geoturismo e sua importância para o desenvolvimento econômico local e a conservação da geodiversidade.

O geoturismo é centrado no conceito de geodiversidade, isto porque os recursos naturais utilizados para sua prática estão relacionados com a visitação, apreciação e educação dos elementos do meio abiótico (Zanatto et al., 2019), sendo a geodiversidade o equivalente abiótico da biodiversidade, que engloba os elementos da geologia, geomorfologia e solos (Gray, 2013). Parks e Muligan (2010) consideram, também, como elementos da geodiversidade o clima e as características hidrográficas. Dessa forma a geodiversidade é compreendida como a base formadora da biodiversidade, essencial aos serviços ecossistêmicos e participante ativa da evolução da vida no planeta.

Dowling (2010) aponta que o geoturismo ocorre em ambientes variados e promove a conservação do geopatrimônio a partir de medidas sustentáveis, avançando na compreensão, dos geoturistas, da geomorfologia e geologia. Para além desses elementos citados por Dowling, Rodrigues (2009) enfatiza a importância de considerar o geopatrimônio enquanto objeto de usufruto do geoturismo, incluindo os geoturistas, a população local e o valor do patrimônio cultural.

Dowling (2010) aponta algumas características essenciais para que o turismo baseado em elementos abióticos seja realmente considerado como geoturismo. A primeira característica apontada é que o turismo tem que ser relacionado ao geopatrimônio e aos seus processos, podendo ocorrer também no ambiente urbano, 
diferente do ecoturismo que depende estritamente de um ambiente natural para ocorrer. O segundo atributo é a sustentabilidade, entendida como a relação da viabilidade econômica e a conservação do geopatrimônio alvo do turismo. O terceiro ponto é o conteúdo educativo, nesse sentido requer que o geoturista receba uma informação educativa que aprimore sua experiência e ele possa apreciar o geopatrimônio de forma positiva. A quarta característica é o benefício local, ou seja, o envolvimento da população local nas atividades relativas ao turismo, gerando benefícios econômicos, sociais e promovendo a conservação do geoambiente. Por fim, vem a satisfação do turista, relacionada com a experiência positiva na visita e com o conhecimento adquirido.

O geoturismo em cavernas, ou espeleoturismo, possui especificidades devido à singularidade ambiental em que ocorre, tanto pela fragilidade ambiental das cavernas, como pela diversidade geossistêmica presente nos complexos cavernícolas, ou seja, cada caverna se comporta de forma diferente às pressões ambientais sofridas. Nesse sentido o desenvolvimento do geoturismo em ambientes cársticos deve ocorrer levando em conta os processos ecológicos específicos da caverna em que vai ocorrer a visitação, deve-se pensar na acessibilidade e segurança do visitante e na redução dos efeitos negativos possíveis de ocorrer com a abertura da caverna para o turismo (Cigna, 2011).

Portanto, este trabalho vem contribuir com informações para a manutenção da visitação nas cavernas turísticas presentes no Parque Estadual de Terra Ronca, e assim permitir a condução do turismo de forma sustentável e benéfica para a comunidade local e visitantes.

\section{Procedimentos Metodológicos}

Os procedimentos adotados para a realização do estudo consistiram na revisão bibliográfica acerca dos indicadores e do território selecionado, a que se sucedeu o levantamento de dados espaciais e o trabalho de campo com aplicação de protocolo, visando a avaliação dos impactos causados em quatro cavernas oficialmente abertas no Parque Estadual de Terra Ronca.

Os indicadores foram avaliados de acordo com o impacto sofrido a partir de 4 magnitudes: baixa, média, alta e extrema. À magnitude baixa são acrescentados 2 pontos, expressando que a destruição dos recursos naturais é insignificante e que não há possibilidade de esgotamento. 4 pontos são acrescentados se for indicado que o impacto teve uma magnitude média, ou seja, quando os impactos são reversíveis a médio prazo (2 a 10 anos). A magnitude é alta quando os impactos nos recursos naturais são consideráveis, existindo a possibilidade de esgotamento e a recuperação é viável apenas a longo prazo (10 a 50 anos), e neste caso são adicionados 6 pontos. À magnitude extrema são acrescentados 10 pontos, considerando-se que nesta situação os recursos foram degradados e exauridos, havendo pouca ou nenhuma possibilidade de recuperação do ambiente (Donato, 2011; Donato et al., 2014). 
A segunda parte do protocolo, essencialmente quantitativo, define um conjunto diversificado de tipos de impactos potencialmente nocivos para o ambiente/elementos geomorfológicos. Os tipos de impacto são separados em 11 categorias, sendo elas:

- Completa destruição da caverna;

- Destruição parcial da caverna, quando parte da caverna é de alguma forma destruída;

- Mudanças na dinâmica hídrica, diminuição do aquífero, inundação, secagem de lagos e lagoas, destruição de áreas de recarga, obstrução de dutos e consequente inundação ou secagem;

- Mudanças no carste: rachaduras, deslocamentos, espeleotemas quebrados, descoloração dos espeleotemas, colapso das estruturas cársticas;

- Mudanças na subsuperfície do solo, como pisoteio de formações delicadas e compactação do solo;

- Poluição sonora: sobreposição acústica e vibração;

- Assoreamento;

- Desmatamento da vegetação natural pelo fogo, redução da matéria orgânica, aumento de espécies exóticas, acidificação do solo, propagação de poluentes;

- Trabalhos de alvenaria, iluminação, calçadas, alterações microclimáticas;

- Visitação desordenada/ vandalismo: lixo, pichação e outros tipos de vandalismo;

- Alcance do impacto, tendo em conta a ação mais impactante: se não houver nenhum impacto, adicionam-se 0 pontos. Se o impacto é local, adicionam-se mais 5 pontos. Quando regional, adicionam-se mais 10 pontos.

Quando o efeito é restrito para o local de ação, o impacto é definido como local. Regional refere-se ao efeito espalhado por uma área além da vizinhança imediata do local onde a ação acontece. O resultado obtido no protocolo é expresso em porcentagem, e a partir deste podem-se classificar seis categorias de níveis de impacto ambiental (Donato, 2011; Donato et al., 2014). São elas:

- Intacta (I): comunidades naturais, populações e processos ecológicos aparentemente intactos, sem ameaças e alterações antrópicas. Pontuação $\leq 7$;

- Estável (E): alterações antrópicas perceptíveis, passíveis de provocar o declínio de populações locais. Processos ecológicos aparentemente intactos. Pontuação: 8 a 34 pontos;

- Vulnerável (VU): risco de extinção do afloramento caso medidas de proteção não sejam tomadas. Habitats degradados. Pontuação: 35 a 61 pontos;

- Em perigo (EP): afloramento com alto risco de extinção. Perda e degradação de habitats, processos ecológicos comprometidos. Pontuação: 62 a 84 pontos;

- Criticamente em perigo (CP): Afloramento com risco extremamente alto de extinção. Grandes alterações na paisagem do entorno, ou matriz, comprometendo a manutenção dos processos ecológicos e espécies nativas. Pontuação: 85 a 99;

- Extinta (EX): caverna extinta. Pontuação: 100. 


\section{Desenvolvimento}

\subsection{Avaliação dos Impactos na Caverna Terra Ronca}

Os impactos no ambiente cavernícola (Figura 2) são observados principalmente no início da caverna, por ocorrer nessa área a maior parte das visitas, tanto turísticas como religiosas. As instalações próximas ao altar estão danificadas, assim como uma das passagens construídas para auxiliar os turistas na travessia da caverna.

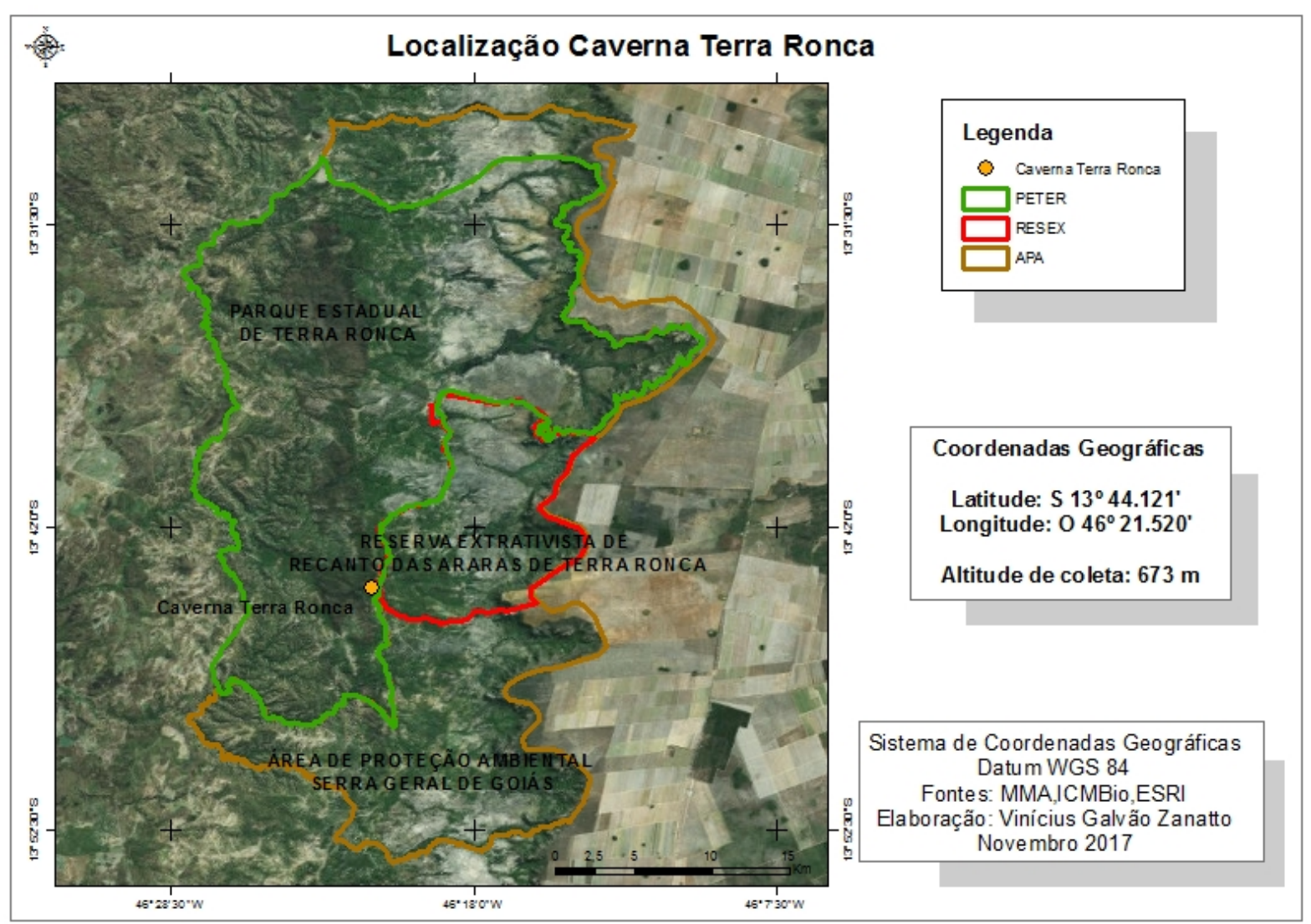

Figura 2: Localização Caverna Terra Ronca.

Existe uma pequena escada de concreto e com corrimão feito de cordas. Essas alterações no ambiente cavernícola são visualmente contrastantes com as características naturais da caverna. A escada é uma intervenção permanente, sua remoção poderia causar mais impactos negativos do que positivos, isso porque ela está incrustada nas formações rochosas. Pode-se observar o pisoteio do chão que causou a compactação do solo e a deformação de espeleotemas.

A parte posterior da caverna Terra Ronca está mais bem preservada que sua entrada, há grande presença de estalactites e maior variedade de formações; a mata de galeria desta área também está mais preservada. O pisoteio do solo ocorre somente na trilha em que a visitação acontece. Nos arredores da caverna ocorre a criação de gado e frequentemente esses rebanhos saem dos pastos delimitados nas fazendas e se dirigem ao rio Lapa, que forma a caverna Terra Ronca. Os rebanhos causam a compactação do solo pelo pisoteio e a destruição da vegetação ripária. 
As principais alterações estão relacionadas com o meio abiótico da caverna, como degradação dos espeleotemas, pisoteio e compactação do solo. Foram encontrados impactos relacionados com a degradação da vegetação próxima a cavidade avaliada, como a mata de galeria parcialmente degradada, próxima à entrada da caverna, e a ocorrência de incêndios na floresta estacional decidual presente acima da cavidade.

A poluição sonora ocorre devido à estrada existente próximo da caverna, não sendo, entretanto, significativa. O maior impacto causado pela poluição sonora ocorre durante os festejos do Bom Jesus da Lapa, no mês de agosto, quando a missa ocorre dentro da caverna e há uma grande aglomeração de pessoas dentro e nos seus arredores (Figura 3). O barulho é expressamente impactante à avifauna presente na caverna, em especial às araras vermelhas (Ara chloropterus) que nidificam nos paredões. Dificilmente são avistadas, porém nos dias dos festejos ficam agitadas e são vistas com frequência próximas aos ninhos.

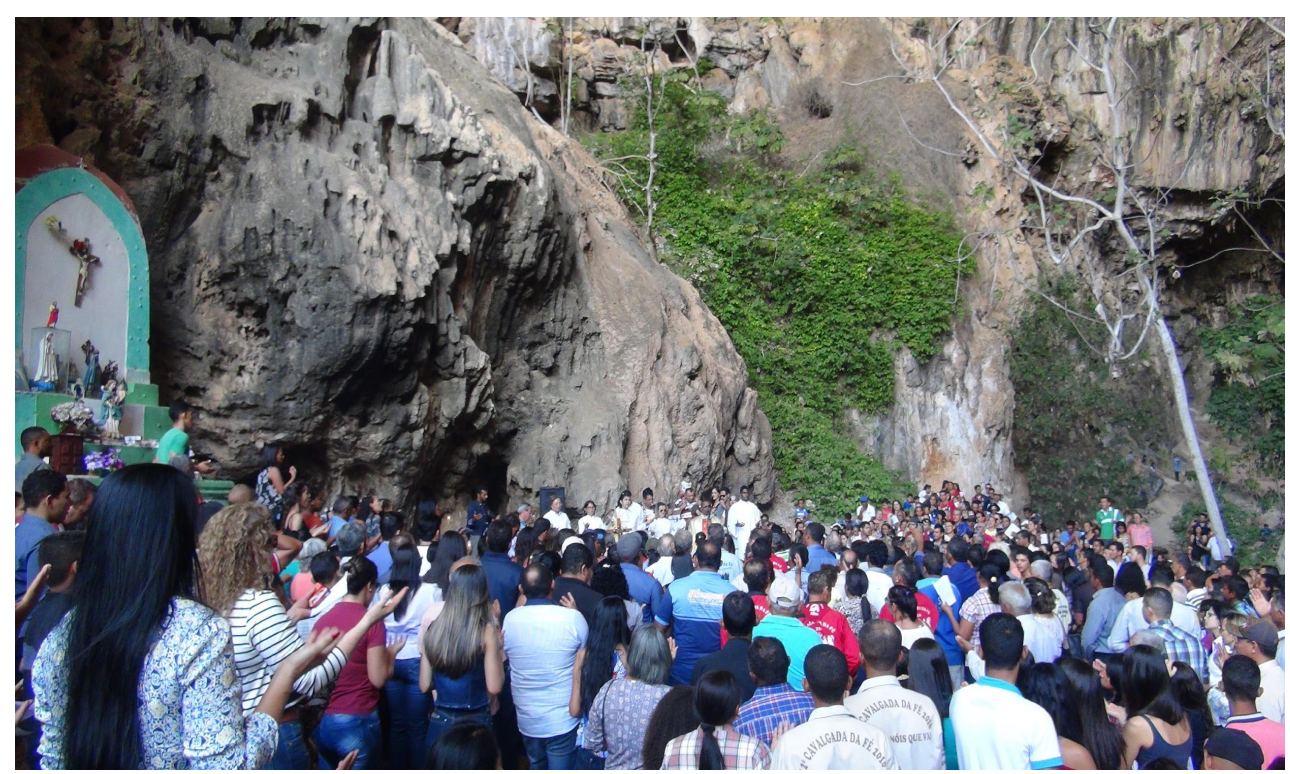

Figura 3: Missa Na Caverna Terra Ronca.

Fonte: Vinícius Zanatto, 2016.

A visitação da Caverna Terra Ronca ocorre sem a presença de guias devido à facilidade do seu acesso e à cultura local de devoção aí existente. Os guias são procurados somente no momento da travessia da cavidade. Devido a essa falta de acompanhamento, muitos visitantes deixam lixos espalhados na entrada da caverna.

Os impactos observados na caverna Terra Ronca se estendem além das imediações da caverna. Seguindo o curso do rio Lapa, a mata de galeria encontra-se parcialmente preservada, tendo ocorrido desmoronamentos em algumas áreas impactando os paredões de calcário, a mata de galeria e os recursos hídricos.

A partir do protocolo de avaliação rápida de impactos na caverna Terra Ronca (Tabela I), verifica-se que as principais atividades causadoras de impacto são a criação de gado e a visitação desordenada. 
Tabela I: Resultado do Protocolo de Avaliação Rápida de Impactos ao Ambiente Cavernícola aplicado à caverna Terra Ronca.

\begin{tabular}{|c|c|c|}
\hline IMPACTO & $\begin{array}{l}\text { PONTUAÇÃO } \\
\text { ESTIMADA }\end{array}$ & $\begin{array}{l}\text { PONTUAÇÃO } \\
\text { OBTIDA }\end{array}$ \\
\hline $\begin{array}{c}\text { Destruição parcial da caverna, quando parte da caverna é de alguma forma } \\
\text { destruída }\end{array}$ & 2/4/6/10 & 4 \\
\hline $\begin{array}{c}\text { Mudanças na dinâmica hídrica, diminuição do aquífero, inundação, secagem } \\
\text { de lagos e lagoas, destruição de áreas de recarga, obstrução de dutos e } \\
\text { consequente inundação ou secagem; }\end{array}$ & 2/4/6/10 & 0 \\
\hline $\begin{array}{c}\text { Mudanças no carste: rachaduras, deslocamentos, espeleotemas quebrados, } \\
\text { descoloração dos espeleotemas, colapso das estruturas cársticas }\end{array}$ & $2 / 4 / 6 / 10$ & 4 \\
\hline $\begin{array}{l}\text { Mudanças na subsuperfície do solo, como pisoteio de formações delicadas e } \\
\text { compactação do solo }\end{array}$ & $2 / 4 / 6 / 10$ & 4 \\
\hline Poluição sonora: sobreposição acústica e vibração & $2 / 4 / 6 / 10$ & 2 \\
\hline Assoreamento & $2 / 4 / 6 / 10$ & 4 \\
\hline $\begin{array}{c}\text { Desmatamento da vegetação natural pelo fogo, redução da matéria } \\
\text { orgânica, aumento de espécies exóticas, acidificação do solo, propagação } \\
\text { de poluentes }\end{array}$ & $2 / 4 / 6 / 10$ & 4 \\
\hline Trabalhos de alvenaria, iluminação, calçadas, alterações microclimáticas & $2 / 4 / 6 / 10$ & 6 \\
\hline $\begin{array}{l}\begin{array}{l}\text { Visitação desordenada/ vandalismo: lixo, pichação e outros tipos de } \\
\text { vandalismo }\end{array}\end{array}$ & 2/4/6/10 & 2 \\
\hline $\begin{array}{l}\text { Alcance do impacto, tendo em conta a ação mais impactante: Se não houver } \\
\text { nenhum impacto não serão adicionados pontos. Se o impacto é local serão } \\
\text { adicionados } 5 \text { pontos. Se o impacto é regional serão acrescentados } 10 \\
\text { pontos. Local: quando o efeito é restrito para o local de ação; Regional: } \\
\text { quando o efeito é espalhado por uma área além da vizinhança imediata do } \\
\text { local onde a ação acontece }\end{array}$ & $0 / 5 / 10$ & 10 \\
\hline
\end{tabular}

Da avaliação efetuada, constata-se que ela foi classificada como vulnerável, atingindo 40 pontos na escala determinada. Essa pontuação indica a perda de habitat e impactos antrópicos perceptíveis. Devido à magnitude da cavidade não há risco de desaparecimento, entretanto as formações internas da caverna e os processos relativos à formação destes estão comprometidos.

\subsection{Avaliação dos Impactos na Caverna Terra Ronca II}

A caverna Terra Ronca II (Figura 4) possui um caráter cênico singular, pois existem diversas formações espeleológicas presentes no trajeto para se adentrar a caverna e no seu interior. A caverna encontra-se em estado natural, não existem modificações como construções, escadas ou iluminação artificial. Entretanto existem demarcações de caminhos feitos por guias com as carbureteiras e alguns espeleotemas pisoteados. 


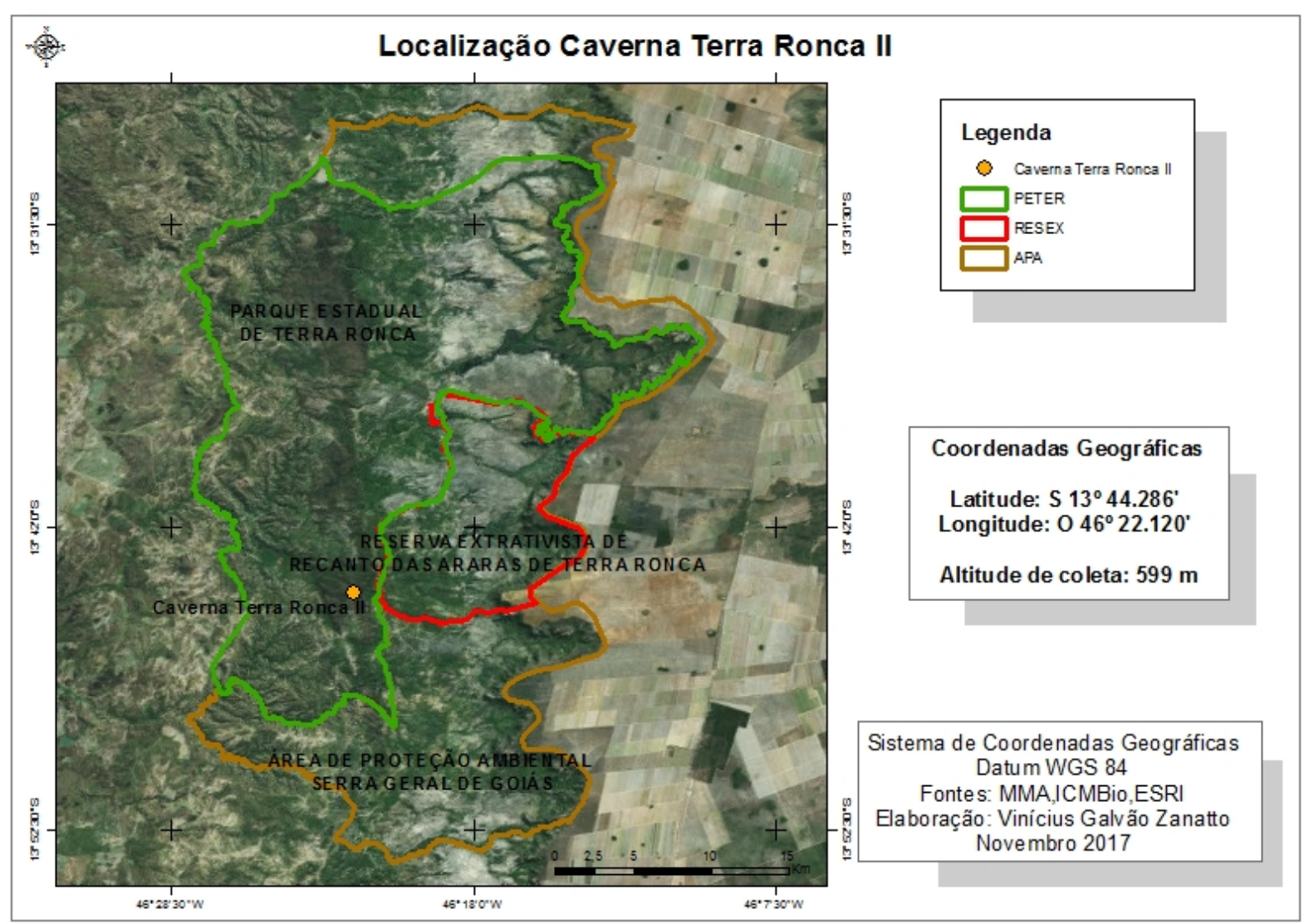

Figura 4: Localização da Caverna Terra Ronca II.

A fauna presente no interior e nas imediações da caverna é diversa, sendo composta por vertebrados, invertebrados e espécies com troglomorfismo. Existem ninhos de araras vermelhas (Ara chloropterus) na parte superior da boca da caverna, populações de morcegos no interior, além de possuir pelo menos uma espécie troglóbia endêmica, como descrito por Simões (2013). Dentre as cavernas avaliadas a caverna Terra Ronca II possui os maiores índices de riqueza, abundância e diversidade de espécies (Simões, 2013).

A mata que recobre suas imediações é nativa, entretanto, como nas outras áreas amostradas, sofreu impactos pela ocorrência de incêndios florestais. Na verdade, foi a caverna mais impactada por esse fenômeno durante a elaboração da pesquisa. Os impactos causados pelos incêndios estão relacionados com os desmoronamentos que ocorreram nas proximidades da caverna. Com a retirada da vegetação, o solo ficou exposto às intempéries e no período chuvoso ocorreu erosão laminar. Os sedimentos oriundos desta erosão foram carregados até o rio Lapa - que dá origem a caverna. Devido aos sedimentos e ao uso e ocupação dos solos nas vertentes da Serra Geral de Goiás, este rio encontra-se assoreado.

Apesar dos descolamentos e desmoronamentos serem fenômenos naturais à própria formação das cavernas, acontecimentos como incêndios e/ou desmatamentos aceleram os processos, causando diversos danos e modificações no ecossistema associado às cavidades naturais que pode ocasionar a perda de geodiversidade. $A$ partir do protocolo aplicado (Tabela II), a caverna foi classificada como estável 
atingindo, 34 pontos dentro da escala estabelecida. Isto significa que pode haver o declínio de populações locais devido às alterações antrópicas, mas os processos ecológicos estão aparentemente intactos.

Tabela II: Resultado do Protocolo de Avaliação Rápida de Impactos ao Ambiente Cavernícola aplicado à caverna Terra Ronca II.

\begin{tabular}{|c|c|c|}
\hline IMPACTO & $\begin{array}{l}\text { PONTUAÇÃO } \\
\text { ESTIMADA }\end{array}$ & $\begin{array}{l}\text { PONTUAÇÃO } \\
\text { OBTIDA }\end{array}$ \\
\hline $\begin{array}{l}\text { Destruição parcial da caverna, quando parte da caverna é de alguma } \\
\text { forma destruída }\end{array}$ & $2 / 4 / 6 / 10$ & 0 \\
\hline $\begin{array}{l}\text { Mudanças na dinâmica hídrica, diminuição do aquífero, inundação, } \\
\text { secagem de lagos e lagoas, destruição de áreas de recarga, obstrução } \\
\text { de dutos e consequente inundação ou secagem; }\end{array}$ & $2 / 4 / 6 / 10$ & 4 \\
\hline $\begin{array}{c}\text { Mudanças no carste: rachaduras, deslocamentos, espeleotemas } \\
\text { quebrados, descoloração dos espeleotemas, colapso das estruturas } \\
\text { cársticas }\end{array}$ & 2/4/6/10 & 4 \\
\hline $\begin{array}{l}\text { Mudanças na subsuperfície do solo, como pisoteio de formações } \\
\text { delicadas e compactação do solo }\end{array}$ & $2 / 4 / 6 / 10$ & 2 \\
\hline Poluição sonora: sobreposição acústica e vibração & 2/4/6/10 & 0 \\
\hline Assoreamento & 2/4/6/10 & 6 \\
\hline $\begin{array}{c}\text { Desmatamento da vegetação natural pelo fogo, redução da matéria } \\
\text { orgânica, aumento de espécies exóticas, acidificação do solo, } \\
\text { propagação de poluentes }\end{array}$ & 2/4/6/10 & 6 \\
\hline Trabalhos de alvenaria, iluminação, calçadas, alterações microclimáticas & 2/4/6/10 & 0 \\
\hline $\begin{array}{c}\text { Visitação desordenada/ vandalismo: lixo, pichação e outros tipos de } \\
\text { vandalismo }\end{array}$ & $2 / 4 / 6 / 10$ & 2 \\
\hline $\begin{array}{l}\text { Alcance do impacto, tendo em conta a ação mais impactante: Se não } \\
\text { houver nenhum impacto não serão adicionados pontos. Se o impacto é } \\
\text { local serão adicionados } 5 \text { pontos. Se o impacto é regional serão } \\
\text { acrescentados } 10 \text { pontos. Local: quando o efeito é restrito para o local } \\
\text { de ação; Regional: quando o efeito é espalhado por uma área além da } \\
\text { vizinhança imediata do local onde a ação acontece }\end{array}$ & 0/5/10 & 10 \\
\hline
\end{tabular}

Essa pontuação está no limite da escala estabelecida, indicando que se não forem tomadas medidas imediatas as populações correm risco de diminuição ou desaparecimento.

\subsection{Avaliação dos Impactos na São Bernardo}

Nesta caverna (Figura 5) há ocorrência de espécies endêmicas, como o caso do peixe Ituglanis ramiroi, demonstrando a importância de sua preservação. Os impactos encontrados na caverna estão associados, principalmente, à visitação que ocorre em seu interior, já que é possível observar espeleotemas danificados. 


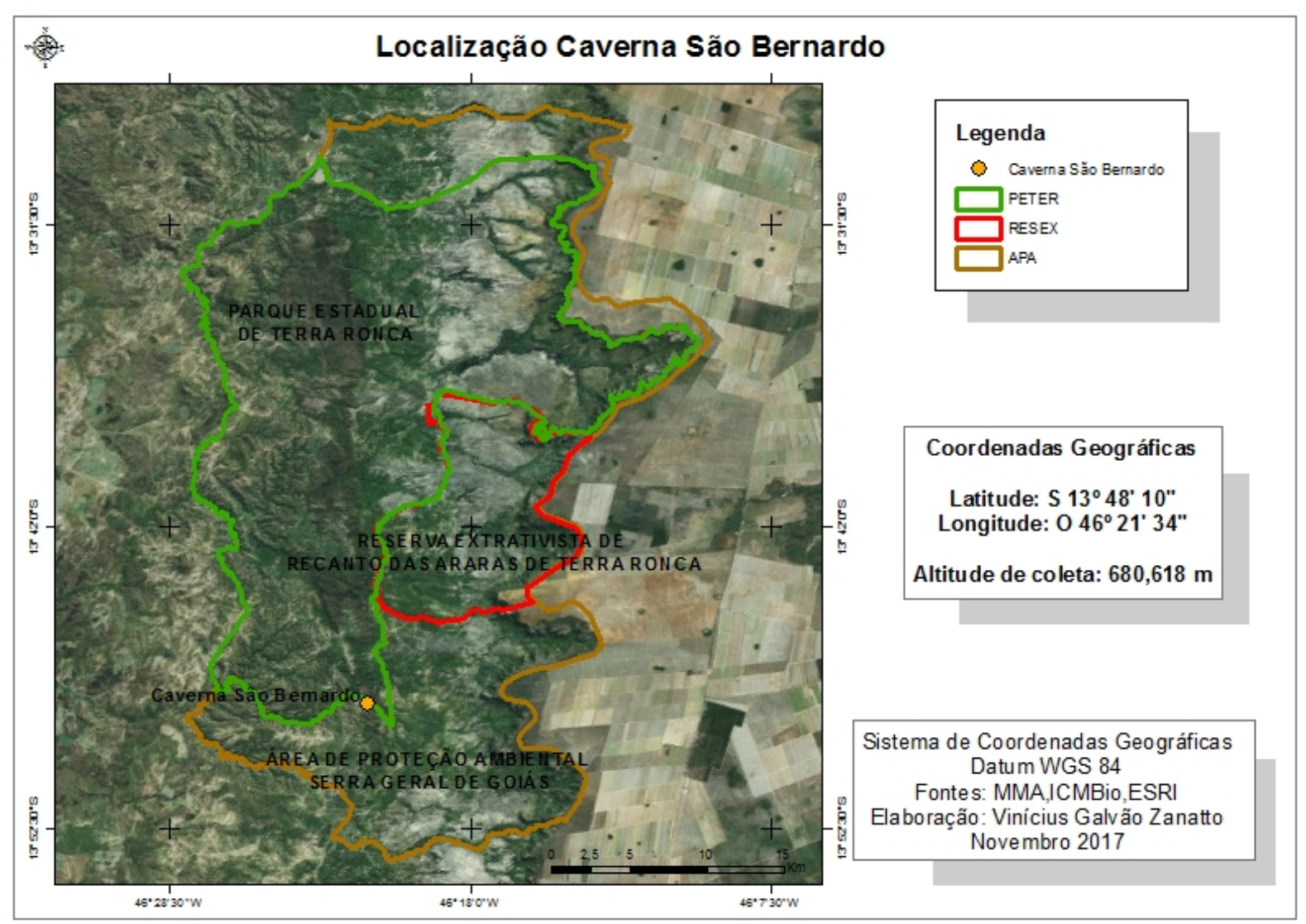

Figura 5: Localização da Caverna São Bernardo.

Diversos guias da região ainda utilizam capacetes com carbureteiras durante as visitas às cavernas, e este equipamento gera múltiplos impactos, desde a liberação de gases dentro do ambiente cavernícola até o comprometimento do desenvolvimento dos espeleotemas (Lobo et al., 2015). Diversos espeleotemas apresentam marcas de fogo, causados por alguns guias que, para demarcar o caminho a ser seguido na caverna, utilizam a carbureteira para demarcar o trajeto. Outro impacto está relacionado a utilização de carbureteiras, especificamente nos resíduos produzidos por elas. Durante as visitas com utilização de carbureteiras, é comum que essas fiquem obstruídas. No intuito de desobstruir o equipamento os guias retiram parte do carbureto do recipiente e o resíduo fica incrustado nas formações.

Impactos relacionados ao pisoteio das estruturas são observados por toda a caverna, uma vez que formações como as pérolas de calcita são visivelmente danificadas pela passagem de pessoas nas estruturas ou próxima a elas. Por ocorrer o pisoteio e a visita desordenada de pessoas na caverna, os guias da região estão realizando intervenções para restringir e ordenar as visitas em seu interior, sendo que tais ações consistem em demarcar os caminhos com cordas (Figura 6). Essas intervenções são positivas no interior da caverna pois não são visualmente contrastantes com o local e não são permanentes, podendo ser retiradas caso seja necessário. 


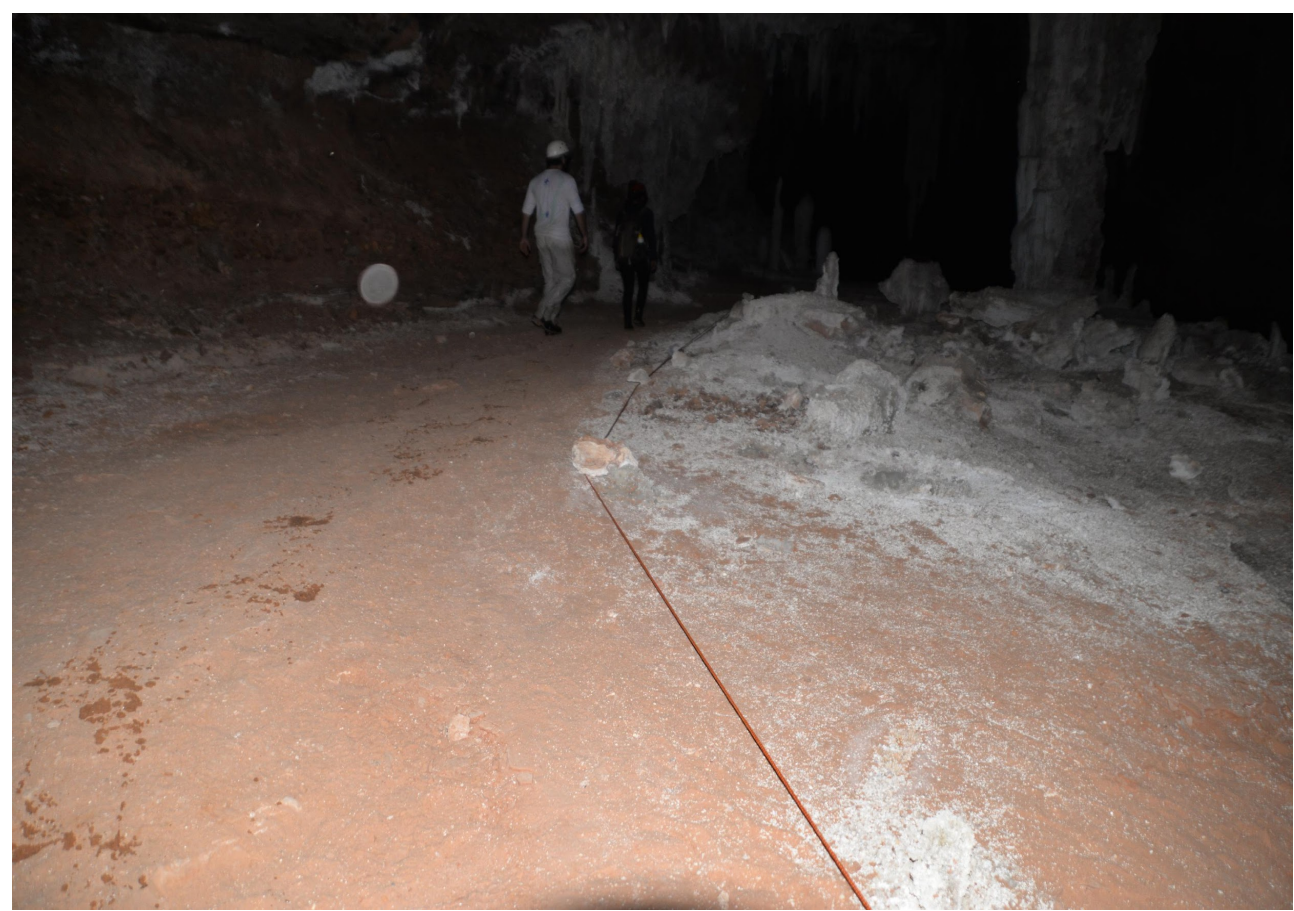

Figura 6: Demarcação de caminhos na Caverna São Bernardo.

Fonte: Vinícius Zanatto. 2017.

A maioria dos impactos observados na caverna São Bernardo provém da má condução do turismo, diversos espeleotemas estão perdendo a sua cor natural, há o pisoteio de formações delicadas e marcações em algumas formações. Na área externa da caverna a vegetação nativa está parcialmente preservada, pois não ocorrem plantações nem criação de gado nas proximidades da entrada da caverna, não há estradas próximas e os visitantes percorrem uma trilha para chegar à boca da caverna, pelo que dessa forma os impactos são menos significativos.

Entretanto, podem ser observados impactos gerados a partir de incêndios florestais que atingiram a região. Os impactos causados pelo fogo na vegetação e no solo influenciam nos processos que ocorrem no interior da caverna, como a quantidade de sedimentos que entram na caverna e a infiltração da água. Ocorre ainda o assoreamento dos rios que formam a caverna, mas no seu interior este impacto ainda não é observado, já que o assoreamento ocorre a montante do canal, o que promove alterações antrópicas na caverna.

A partir do protocolo aplicado (Tabela III) a caverna foi classificada como estável, atingindo 29 pontos dentro da escala estabelecida, significando que pode haver o declínio de populações locais devido às alterações antrópicas. Entretanto, os processos ecológicos estão aparentemente intactos. A pontuação baixa é um fator positivo para a manutenção da visitação da caverna, necessitando somente algumas mudanças de atitudes em relação aos cuidados com o desenvolvimento do turismo. Os danos causados nas pérolas de calcita e em outras formações são irreversíveis, entretanto existem outras danificações que podem ser remediadas com o isolamento da área e com a limpeza de algumas formações. 
Tabela III: Resultado Protocolo de Avaliação Rápida de Impactos ao Ambiente Cavernícola aplicado à caverna São Bernardo.

\begin{tabular}{|c|c|c|}
\hline IMPACTO & $\begin{array}{l}\text { PONTUAÇÃO } \\
\text { ESTIMADA }\end{array}$ & $\begin{array}{c}\text { PONTUAÇÃO } \\
\text { OBTIDA }\end{array}$ \\
\hline $\begin{array}{l}\text { Destruição parcial da caverna, quando parte da caverna é de alguma } \\
\text { forma destruída }\end{array}$ & $2 / 4 / 6 / 10$ & 0 \\
\hline $\begin{array}{l}\text { Mudanças na dinâmica hídrica, diminuição do aquífero, inundação, } \\
\text { secagem de lagos e lagoas, destruição de áreas de recarga, obstrução } \\
\text { de dutos e consequente inundação ou secagem; }\end{array}$ & 2/4/6/10 & 0 \\
\hline $\begin{array}{c}\text { Mudanças no carste: rachaduras, deslocamentos, espeleotemas } \\
\text { quebrados, descoloração dos espeleotemas, colapso das estruturas } \\
\text { cársticas }\end{array}$ & 2/4/6/10 & 10 \\
\hline $\begin{array}{c}\text { Mudanças na subsuperfície do solo, como pisoteio de formações } \\
\text { delicadas e compactação do solo }\end{array}$ & 2/4/6/10 & 4 \\
\hline Poluição sonora: sobreposição acústica e vibração & $2 / 4 / 6 / 10$ & 0 \\
\hline Assoreamento & $2 / 4 / 6 / 10$ & 4 \\
\hline $\begin{array}{c}\text { Desmatamento da vegetação natural pelo fogo, redução da matéria } \\
\text { orgânica, aumento de espécies exóticas, acidificação do solo, } \\
\text { propagação de poluentes }\end{array}$ & $2 / 4 / 6 / 10$ & 0 \\
\hline Trabalhos de alvenaria, iluminação, calçadas, alterações microclimáticas & 2/4/6/10 & 4 \\
\hline $\begin{array}{c}\text { Visitação desordenada/ vandalismo: lixo, pichação e outros tipos de } \\
\text { vandalismo }\end{array}$ & 2/4/6/10 & 2 \\
\hline $\begin{array}{l}\text { Alcance do impacto, tendo em conta a ação mais impactante: Se não } \\
\text { houver nenhum impacto não serão adicionados pontos. Se o impacto é } \\
\text { local serão adicionados } 5 \text { pontos. Se o impacto é regional serão } \\
\text { acrescentados } 10 \text { pontos. Local: quando o efeito é restrito para o local de } \\
\text { ação; Regional: quando o efeito é espalhado por uma área além da } \\
\text { vizinhança imediata do local onde a ação acontece }\end{array}$ & $0 / 5 / 10$ & 5 \\
\hline
\end{tabular}

\subsection{Avaliação dos Impactos na Caverna São Mateus}

A caverna São Mateus (Figura 7) recebe o mesmo nome do rio que a forma. Essa caverna integra um grande sistema de cavidades que origina a $8^{\mathrm{a}}$ maior caverna do Brasil, com mais de 10 quilômetros de extensão. Devido à variedade e fragilidade dos espeleotemas presentes nessa cavidade, a visitação deve ser restrita a poucos locais e com grupos pequenos. A caverna está inserida em uma área que possui diversas inscrições rupestres no seu entorno, indicando grande importância patrimonial.

A caverna resguarda suas características naturais, não existem calçadas, iluminação ou trabalhos de alvenaria que geram impactos. Não está próxima às estradas, plantações ou criações de gado e a vegetação que recobre a área é nativa. Entretanto, impactos do fogo podem ser observados, além de diversos indícios de extração ilegal de madeira nas proximidades. 


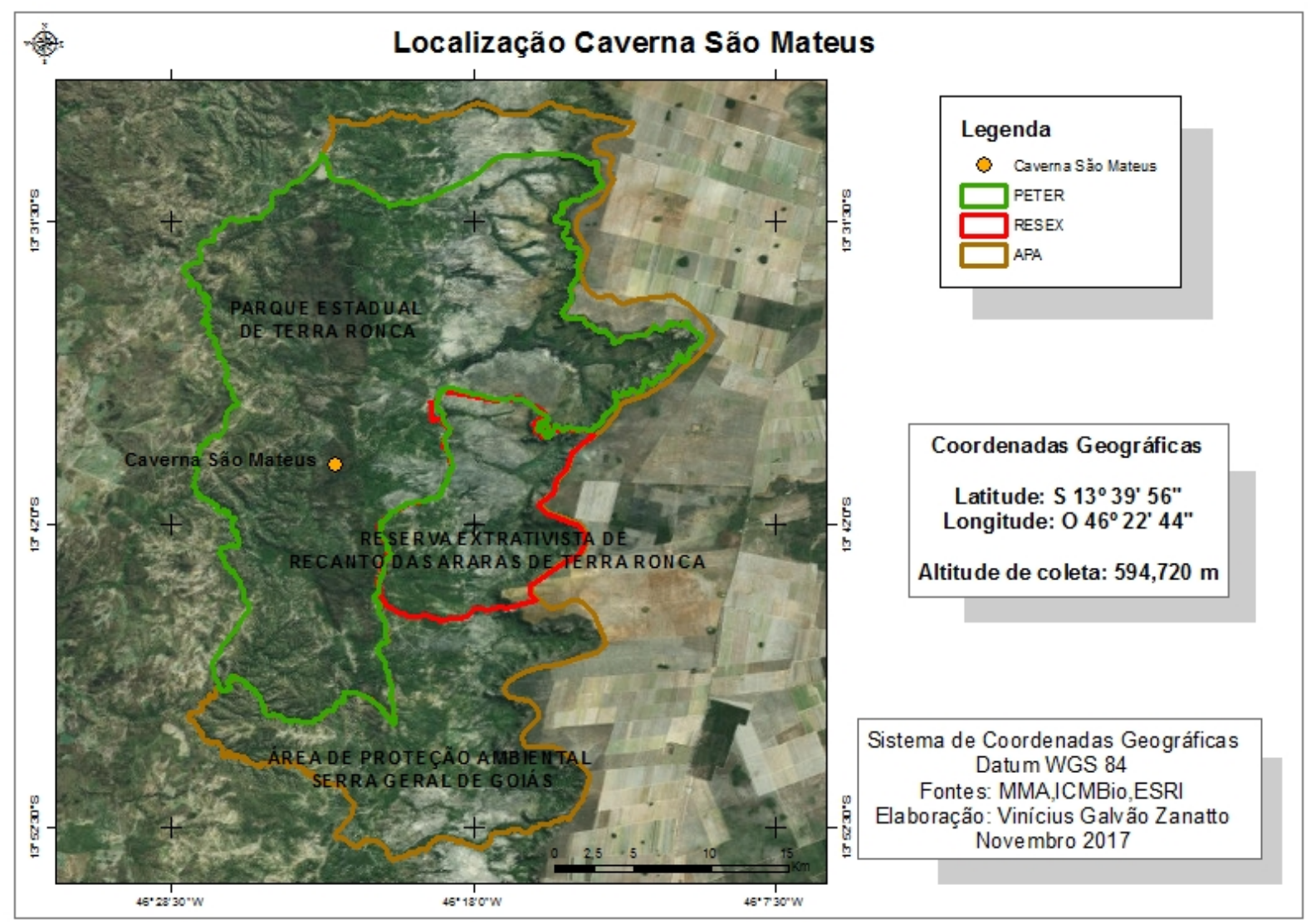

Figura 7: Localização da Caverna São Mateus.

A visitação desordenada é um problema nessa caverna, assim como nas outras avaliadas, e podem ser observadas marcas de carbureteira demarcando caminhos e impactos causados pela aproximação dos visitantes nos espeleotemas, que acabam por queimar as formações quando se aproximam. O pisoteio de formações delicadas também é visível, em especial no salão 700.

A fauna presente na caverna São Mateus é diversa. No que tange aos invertebrados, Simões (2013) aponta que existem 42 espécies de invertebrados. Dentre as espécies descritas na caverna uma que se destaca é o peixe Ituglanis epikarticus, endêmico dessa cavidade. A espécie consta na lista de espécies ameaçadas sendo classificada como vulnerável (VU), e vive nos travertinos da caverna. Com um meio de vida restrito, qualquer mudança ambiental na caverna pode causar danos irreversíveis à espécie citada.

A partir do protocolo aplicado (Tabela IV) a caverna foi classificada como estável, atingindo 21 pontos dentro da escala estabelecida, o que significa que pode haver 0 declínio de populações locais devido às alterações antrópicas. Entretanto, os processos ecológicos estão aparentemente intactos. Essa caverna é a que possui a maior diversidade de espeleotemas, conta com uma diversidade de espécies significativa e, apesar ter recebido as menores notas na avaliação de impacto, é a mais frágil. Portanto, medidas de monitoramento devem ser tomadas para que a biodiversidade e a geodiversidade da caverna se mantenham estáveis. 
Tabela IV: Resultado do Protocolo de Avaliação Rápida de Impactos ao Ambiente Cavernícola aplicado à caverna São Mateus.

\begin{tabular}{|c|c|c|}
\hline IMPACTO & $\begin{array}{l}\text { PONTUAÇÃO } \\
\text { ESTIMADA }\end{array}$ & $\begin{array}{l}\text { PONTUAÇÃO } \\
\text { OBTIDA }\end{array}$ \\
\hline $\begin{array}{l}\text { Destruição parcial da caverna, quando parte da caverna é de alguma } \\
\text { forma destruída. }\end{array}$ & $2 / 4 / 6 / 10$ & 0 \\
\hline $\begin{array}{l}\text { Mudanças na dinâmica hídrica, diminuição do aquífero, inundação, } \\
\text { secagem de lagos e lagoas, destruição de áreas de recarga, obstrução de } \\
\text { dutos e consequente inundação ou secagem; }\end{array}$ & $2 / 4 / 6 / 10$ & 0 \\
\hline $\begin{array}{c}\text { Mudanças no carste: rachaduras, deslocamentos, espeleotemas } \\
\text { quebrados, descoloração dos espeleotemas, colapso das estruturas } \\
\text { cársticas }\end{array}$ & $2 / 4 / 6 / 10$ & 4 \\
\hline $\begin{array}{c}\text { Mudanças na subsuperfície do solo, como pisoteio de formações } \\
\text { delicadas e compactação do solo }\end{array}$ & $2 / 4 / 6 / 10$ & 2 \\
\hline Poluição sonora: sobreposição acústica e vibração & $2 / 4 / 6 / 10$ & 0 \\
\hline Assoreamento & $2 / 4 / 6 / 10$ & 4 \\
\hline $\begin{array}{l}\text { Desmatamento da vegetação natural pelo fogo, redução da matéria } \\
\text { orgânica, aumento de espécies exóticas, acidificação do solo, propagação } \\
\text { de poluentes }\end{array}$ & 2/4/6/10 & 4 \\
\hline Trabalhos de alvenaria, iluminação, calçadas, alterações microclimáticas & $2 / 4 / 6 / 10$ & 0 \\
\hline $\begin{array}{c}\begin{array}{c}\text { Visitação desordenada/ vandalismo: lixo, pichação e outros tipos de } \\
\text { vandalismo }\end{array}\end{array}$ & $2 / 4 / 6 / 10$ & 2 \\
\hline $\begin{array}{l}\text { Alcance do impacto, tendo em conta a ação mais impactante: Se não } \\
\text { houver nenhum impacto não serão adicionados pontos. Se o impacto é } \\
\text { local serão adicionados } 5 \text { pontos. Se o impacto é regional serão } \\
\text { acrescentados } 10 \text { pontos. Local: quando o efeito é restrito para o local de } \\
\text { ação; Regional: quando o efeito é espalhado por uma área além da } \\
\text { vizinhança imediata do local onde a ação acontece }\end{array}$ & $0 / 5 / 10$ & 5 \\
\hline
\end{tabular}

\section{Conclusões}

É possível enquadrar as cavernas em diversas formas de patrimônio, como indicam Lobo e Boggiani (2013). Dessa forma, elas devem ter planos de conservação implantados que visem as atividades turísticas de maneira a evitar novas degradações e avanço das já existentes. Desta maneira, o uso de indicadores para diagnóstico é uma das técnicas que melhor auxiliam no monitoramento de mudanças dos processos naturais e antrópicos, permitindo sua avaliação e formulação de políticas ambientais adequadas.

Em seu trabalho Donato et al. (2014) apontam que estes indicadores servem também para áreas que demandam ações mais urgentes, isto é, rápida restauração do ambiente. Assim, esse tipo de estudo serve principalmente como indicação das vulnerabilidades ambientais. Em Terra Ronca foi possível aplicar estes indicadores nas quatro principais cavernas turísticas da região, chegando aos seguintes valores de impactos: São Mateus - 21, São Bernardo - 29 Terra Ronca II - 34 e Terra Ronca 40 , onde esta última apresenta maiores impactos por diversos motivos, como o 
turismo, atividades agropastoris, degradação de espeleotemas e incêndios florestais. Alguns destes impactos podem ser contornados. Todavia, outros são mais complexos de serem resolvidos, como é o caso das pérolas de calcita na Caverna São Bernardo.

Os protocolos de avaliação de impactos nas cavernas demonstraram a fragilidade dos ambientes avaliados e que o turismo vem ocorrendo de forma desordenada. O plano emergencial elaborado em 2012 não é uma ferramenta completa para regular o uso turístico das cavernas e necessita de atualização.

A implementação do plano de manejo, específico para cada caverna, é urgente, visto que esse documento é fundamental para guiar as ações de manejo e monitoramento das cavernas em questão. Importante destacar que além de tais iniciativas é preciso estabelecer programas paralelos de educação e difusão da importância destes geossistemas, propiciando conhecimento da sociedade em geral sobre cavernas e sua conservação.

\section{Agradecimentos}

Ao Laboratório de Geoiconografia e Multimídias (LAGIM) pela infraestrutura disponibilizada.

Coordenação de Aperfeiçoamento de Pessoal de Nível Superior - CAPES em forma de bolsa de estudos.

\section{Bibliografia}

Cigna, A. A. (2011). Show Cave Development with Special References to Active Caves. Tourism and Karst Areas, 4(1), 7-16. Disponível em: http://www.cavernas.org.br/ptpc/tka v4 n1 007-016.pdf

Donato, C. R. (2011). Análise de impacto sobre as cavernas e seu entorno no município de Laranjeiras, Sergipe. Dissertação de Mestrado em Desenvolvimento e Meio Ambiente, Universidade Federal de Sergipe, São Cristovão.

Donato, C. R., Ribeiro, A. S., Souto, L. S. (2014). A conservation status index, as an auxiliary tool for the management of cave environments. International Journal of Speleology, 43(3), 315-322. http://dx.doi.org/10.5038/1827-806X.43.3.8

Dowling, R. K. (2010). Geotourism's Global Growth. Geoheritage, 3(1), 1-13. https://doi.org/10.1007/s12371-010-0024-7

Guerra, A. T., Guerra, A. J. (2015). Novo Dicionário Geológico-Geomorfológico. Rio de Janeiro: Bertrand Brasil.

Gray, M. (2013). Geodiversity and the Ecosystem Approach: The Contribution of Geoscience in Delivering Integrated Environmental Management. Proceedings of Geologists Association, 124(4), 659-673. https://doi.org/10.1016/j.pgeola.2013.01.003

Hardt, R. (2008) Sistema cárstico e impactos antrópicos: Considerações sobre o manejo. In: $1^{\circ} \mathrm{SIMPGEO} / \mathrm{SP}$, Rio Claro.

Hobo, F. E. (2011). Viajando por paisagens naturais: a espeleologia como experiência turística. Dissertação de mestrado em Geografia Física, Universidade de São Paulo, São Paulo. 
Lobo, H. A. S., Boggiani, P., Sayeg, I. J., Perinotto, A. J. (2015). Impactos ambientais em espeleotemas causados pela visitação pública com carbureteiras na Caverna Santana (Parque Estadual Turístico do Alto Ribeira, Iporanga-SP). Geociências, 34(1), 103-115. http://www.ppegeo.igc.usp.br/index.php/GEOSP/article/view/8494

Lobo, H. A. S., Boggiani, P. (2013). Cavernas como patrimônio geológico. Boletim Paranaense de Geociências, 70, 190-199. http://dx.doi.org/10.5380/geo.v70i0.31698

Marra, R. J. C. (2001). Espeleo Turismo: Planejamento e Manejo de Cavernas. Brasília: Editora WD Ambiental.

Parks, K. E., Mulligan, M. (2010). On The Relationship Between a Resource based Measure of Geodiversity and Broad Scale Biodiversity Patterns. Biodiversity Conservation, 19, 2751 2766. https://doi.org/10.1007/s10531-010-9876-z

Rodrigues, M. L. (2009). Geodiversidade, Património Geomorfológico e Geoturismo. TERRITUR, Rel. 1, GEOPAGE, CEG, IGOT-UL.

Simões, L. B. (2013). Biodiversidade da Fauna Subterrânea na Área Cárstica de São Domingos, Nordeste de Goiás: Relevância Versus Visibilidade. Dissertação, Universidade Federal de São Carlos, São Carlos.

Zanatto, V. G., Steinke, V. A., Vieira, A. A. B. (2019). Impactos do Geoturismo na Caverna Terra Ronca, Goiás, Brasil. Revista de Geografia e Ordenamento do Território, 16, 391414. http://dx.doi.org/10.17127/got/2019.16.017

Artigo recebido em/ Received on: 07/11/2019

Artigo aceite para publicação em/ Accepted for publication on: 29/12/2019 